\title{
ESTRATIGRAFIA E EVOLUÇÃO GEOMORFOLÓGICA DO GRUPO BAMBUÍ NA REGIÃO DE MORRO DA GARÇA (MG)
}

\author{
Mario Luiz de Sá C. Chaves ${ }^{1}$, Leila Benitez ${ }^{2}$, \\ Kerley Wanderson Andrade $^{3} \&$ Gláucia Nascimento Queiroga ${ }^{4}$
}

RESUMO

\begin{abstract}
O Morro da Garça encontra-se no município homônimo, localizado no centro geodésico do Estado de Minas Gerais. Esse morro constitui uma feição geomorfológica circular ressaltada na planura do cerrado, e que tem servido ao longo dos últimos séculos como guia de referência para os viajantes. Em termos geológicos, tal região é coberta por litotipos do Grupo Bambuí, datados no Neoproterozóico. Na parte mais arrasada do relevo, predominam as formações Lagoa do Jacaré e Serra da Saudade, com as camadas dispostas sub-horizontalmente. No morro em si, um levantamento de detalhe permitiu reconhecer uma seqüência pelito-arenosa que define uma transição entre as formações Serra da Saudade e Três Marias. O topo do morro é sustentado por cerca de $60 \mathrm{~m}$ de metarenitos impuros da Formação Três Marias, no cume bastante recristalizados. Comparações de ordem petrográfica dessas rochas, com as que ocorrem na região de Pirapora, uma das seções-tipo da Formação Três Marias, comprovam tal correlação. Esta situação geológica peculiar permitiu que o morro da Garça fosse preservado como um testemunho na paisagem regional.
\end{abstract}

Palavras-chaves: Morro da Garça; Grupo Bambuí; Estratigrafia; Evolução geomorfológica.

\begin{abstract}
The Garça's hill is located in the Morro da Garça county, on the geodesic center of Minas Gerais State. It is a geomorphological circular feature salient on the plain of the savanna, that has been used in the last centuries as a reference guide to the travelers. Concerning on the geological aspects, this region is covered by the Bambuí Group rocks, of Neoproterozoic age. In the most eroded part of the relief, occurs the Lagoa do Jacaré and the Serra da Saudade formations (undivided), with sub-horizontal layers. A detail survey in the hill allowed to recognizing a pelite-carbonatic sequence that determines a transition between the Serra da Saudade and Três Marias formations. The highest part of the hill is supported by about $60 \mathrm{~m}$ of the Três Marias Formation, that consists of a cristallized and impure sandstone in the peak. Petrographic comparisons of these rocks with others that occur in the Pirapora region, where is located a type section of the Três Marias Formation, prove such correlation. This peculiar geological situation conditioned the preservation of the Garça's hill as a butte in the regional landscape.
\end{abstract}

Keywords: Garça’s hill; Bambui Group; Stratigraphy; Geomorphological evolution.

\section{INTRODUÇÃO}

O Morro da Garça constitui uma estrutura de morfologia circular com 1,6 km de diâmetro, realçada cerca de $350 \mathrm{~m}$ acima de uma região extremamente plana no centro-norte de Minas Gerais. Tal feição ressaltada na paisagem tem servido ao longo dos últimos séculos como um guia de referência para tropas e viajantes e, ao seu sopé desenvolveu-se a cidade de Morro da Garça. O morro ganhou também notoriedade nacional quando, no conto "O Recado do Morro", João Guimarães Rosa deixou uma de suas obras imortais em prosa, ao retratar a percepção de certo visionário sertanejo que julga ter recebido dali uma mensagem de morte (Guimarães Rosa, 1956). Entretanto, em termos geológicos e de evolução fisiográfica, a região é ainda muito pouco conhecida. Desse modo, o presente trabalho tem por fim a caracterização estratigráfica e petrográfica dos diversos litotipos presentes na área do morro, a correlação da seqüência aflorante com a de outras regiões próximas e, tendo por base tal concepção estratigráfica, propor um modelo para a evolução geomorfológica que permitiu a sua preservação como um testemunho na paisagem. Esses estudos tiveram como finalidade inicial a proposição de tal área como um sítio geológico brasileiro (Chaves et al., 2006).

\section{LOCALIZAÇ̃̃O E BREVE HISTÓRICO}

A cidade de Morro da Garça dista cerca de 200 $\mathrm{km}$ de Belo Horizonte, na região centro-norte de Minas Gerais (Figura 1), estando localizada no centro geodésico do estado. $\mathrm{O}$ acesso à mesma se dá, desde a capital, inicialmente pela rodovia BR-040 (Rio-Brasília) até o entroncamento de São José da Lagoa, depois de Paraopeba, quando se toma a BR-135 passando por Curvelo. A cerca de $20 \mathrm{~km}$ desta cidade, por estrada estadual à esquerda com $15 \mathrm{~km}$ de extensão faz-se 


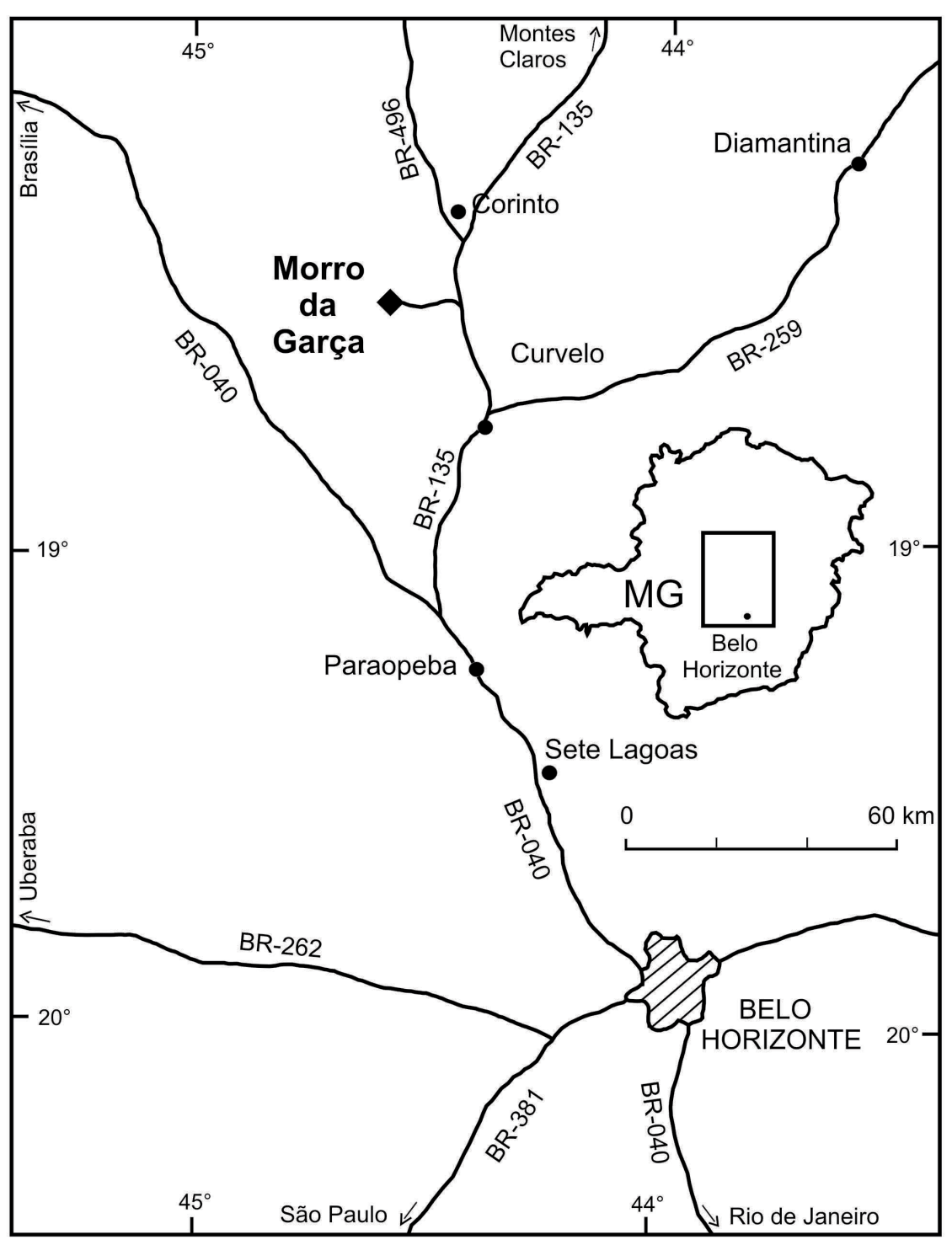

Figura 1: Mapa de localização e acesso à região de Morro da Garça (MG).

a ligação até Morro da Garça. A chegada ao morro homônimo se dá preferencialmente a partir da cidade, por estrada encascalhada em boas condições de tráfego, situando-se a cerca de $2 \mathrm{~km}$ a sudoeste da mesma. A subida ao cume é facilitada por estrada de terra mal conservada, que dá acesso a torre de TV e cruzeiro localizados naquele local.

O povoamento da região de Morro da Garça teve origem no início do século XVIII, como caminho de boiadeiros no circuito entre a Bahia até a vila de Sabará, na porção central da então Província das Minas Gerais (Lima, 1998). A denominação do lugar deveuse à existência da elevação rochosa homônima, a mais elevada da região com cerca de $1.000 \mathrm{~m}$ de altitude, onde ao seu sopé ficava a Fazenda da Garça. Na imensidão plana do cerrado, esse morro serviu ao longo dos últimos três séculos como um guia para viajantes, tropeiros e "comitivas" de gado. Os viajantes faziam parada de descanso na Fazenda da Garça, a última no caminho entre a Bahia e as minas de ouro de Sabará. Segundo Lima (1998), o arraial se formou em torno da capela de Nossa Senhora das Maravilhas, construída em 1720 nas terras da referida fazenda. A cidade foi emancipada somente em 1962, ao se desmembrar do município de Curvelo.

\section{CONTEXTO FISIOGRÁFICO}

A região enfocada está inserida no médio vale do Rio São Francisco, encontrando-se no setor conhecido como "Chapadões do Oeste Mineiro", com vegetação predominantemente composta por campos cerrados onde prevalecem processos morfogenéticos tropicais e mecânicos de ação moderada, característicos das zonas de savanas (Menezes Filho et al., 1977). Durante o Quaternário, ocorreram nessa região intensas variações climáticas, dominando principalmente climas secos com chuvas torrenciais e irregulares, concentrada nos meses de novembro, dezembro e janeiro, que favoreceram a atuação do intemperismo mecânico nas rochas e transporte curto desses detritos formando depósitos alúvio-coluvionares. Como a cobertura vegetal não oferece uma proteção eficaz contra a ação 
erosiva, condiciona-se intenso escoamento superficial, movimentando o material já fragmentado após o longo período de estação seca. De modo geral, a evolução do relevo nos campos cerrados possui certa regularidade. Nas encostas mais íngremes tal evolução se dá por coluvionamento e, nos terrenos mais suaves, a infiltração favorece a decomposição química. Dessa maneira, as superfícies tendem a apresentar aplainamento geral, processo que é facilitado pela disposição estrutural das camadas sedimentares.

Em toda essa porção do centro-norte mineiro, identifica-se facilmente o escalonamento de duas superfícies de erosão. A sucessão de tais níveis seria responsável pela evolução do relevo, com as primeiras observações a respeito feitas por De Martone (1943, 1944) e ampliadas por King (1956), quando foram determinadas diversas superfícies cíclicas regionais. Estudos retomados por Braun (1970), enfatizam que o ciclo "Sul-Americano", já reconhecido por King (1956) e desenvolvido no Oligoceno-Mioceno, é o principal elemento formador da paisagem e que foi somente a partir dessa superfície que o modelado atual foi esculpido. A região dos Chapadões do Oeste Mineiro está nivelada no topo por tal superfície, que secciona rochas neoproterozóicas e cretácicas e, nas baixadas, uma outra superfície mais nova foi designada

de "Velhas", do Plioceno.

De outro modo, Valadão (1998), reconheceu a partir do Mesozóico a existência de três superfícies de aplainamento, designadas de Sul-Americana, Sul-Americana I e Sul-Americana II, com a primeira alcançando estágio de aplainamento mais avançado que as demais. Esse autor considerou a superfície Sul-Americana como desenvolvida em vários estágios desde o Aptiano, e somente encerrada no Mioceno, enquanto as outras duas teriam idades, respectivamente, pliocênica e pleistocênica. Como, para a área em questão as superfícies Sul-Americana e Sul-Americana I de Valadão (1998) são cronológica e espacialmente semelhantes às antes propostas por King (1956), prefere-se aqui manter as designações originais. Relacionando-se então os contextos geomorfológico e geológico, reconhecem-se coberturas indiferenciadas (Plioceno-Pleistoceno) que repousam sobre rochas do Grupo Bambuí, constituindo um solo espesso originado da desintegração de tais rochas, o qual localmente é capeado por depósitos alúvio-coluvionares holocênicos. No Grupo Bambuí, o relevo se diversifica também de acordo com suas litologias e, desse modo, nas fácies pelíticas da seqüência Lagoa do Jacaré - Serra da Saudade, de largo predomínio na região, a morfologia arrasada do relevo contrasta com o "ponto"

\section{Morro da Garça}

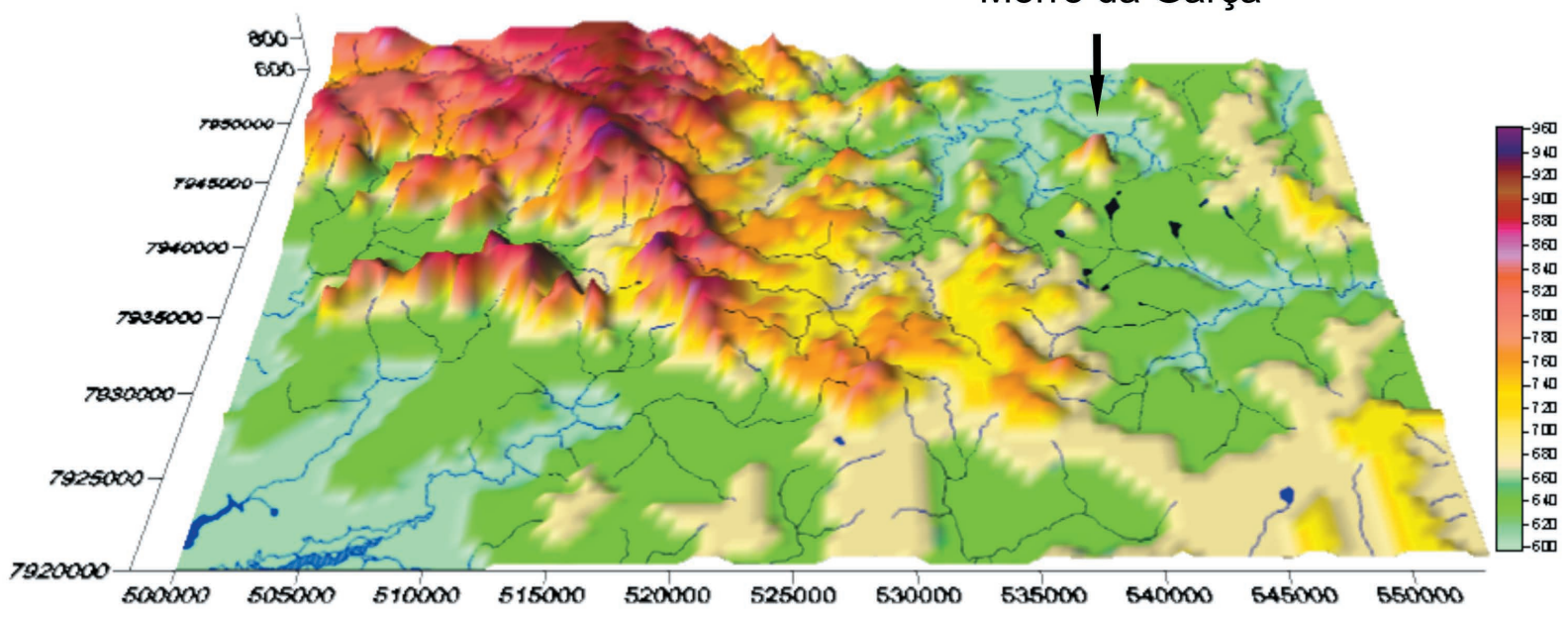

Figura 2: Modelo de elevação digital de terreno da região destacando-se nesse contexto, a nordeste, o morro da Garça. A noroeste, a feição ressaltada no relevo corresponde à Serra do Boiadeiro. Base - Folha Morro da Garça 1:100.000, DSG - Exército Brasileiro (aproximadamente a metade norte da folha).

compreendido pelo morro da Garça, o qual atinge quase $1.000 \mathrm{~m}$ sendo nivelado no topo pela superfície SulAmericana, enquanto a sede do município encontra-se a uma altitude de $600 \mathrm{~m}$ (Figura 2). A razão de existência de tal "ponto" será discutida nos próximos capítulos.

\section{GEOLOGIA}

\section{Aspectos regionais do Grupo Bambuí}

$\mathrm{Na}$ região compreendida entre os municípios de Curvelo e Morro da Garça ocorrem principalmente sedimentos anquimetamorfizados pertencentes ao
Grupo Bambuí (Supergrupo São Francisco), de idade neoproterozóica, além de coberturas detrítico-lateríticas cenozóicas (Figura 3). Não existe qualquer estudo sobre a área em escala maior do que as regionais. De tal modo, o Projeto Três Marias, do convênio DNPM/CPRM, levantou a região na escala 1:250.000, estando a área inserida na Folha Curvelo do mesmo projeto (Menezes Filho et al., 1977).

Os sedimentos pelítico-carbonáticos do Grupo Bambuí foram inicialmente reconhecidos por Derby (1880) como "Série São Francisco". Essa denominação original foi modificada por Rimann (1917), com a expressão "Série Bambuí", que foi consagrada pelo 


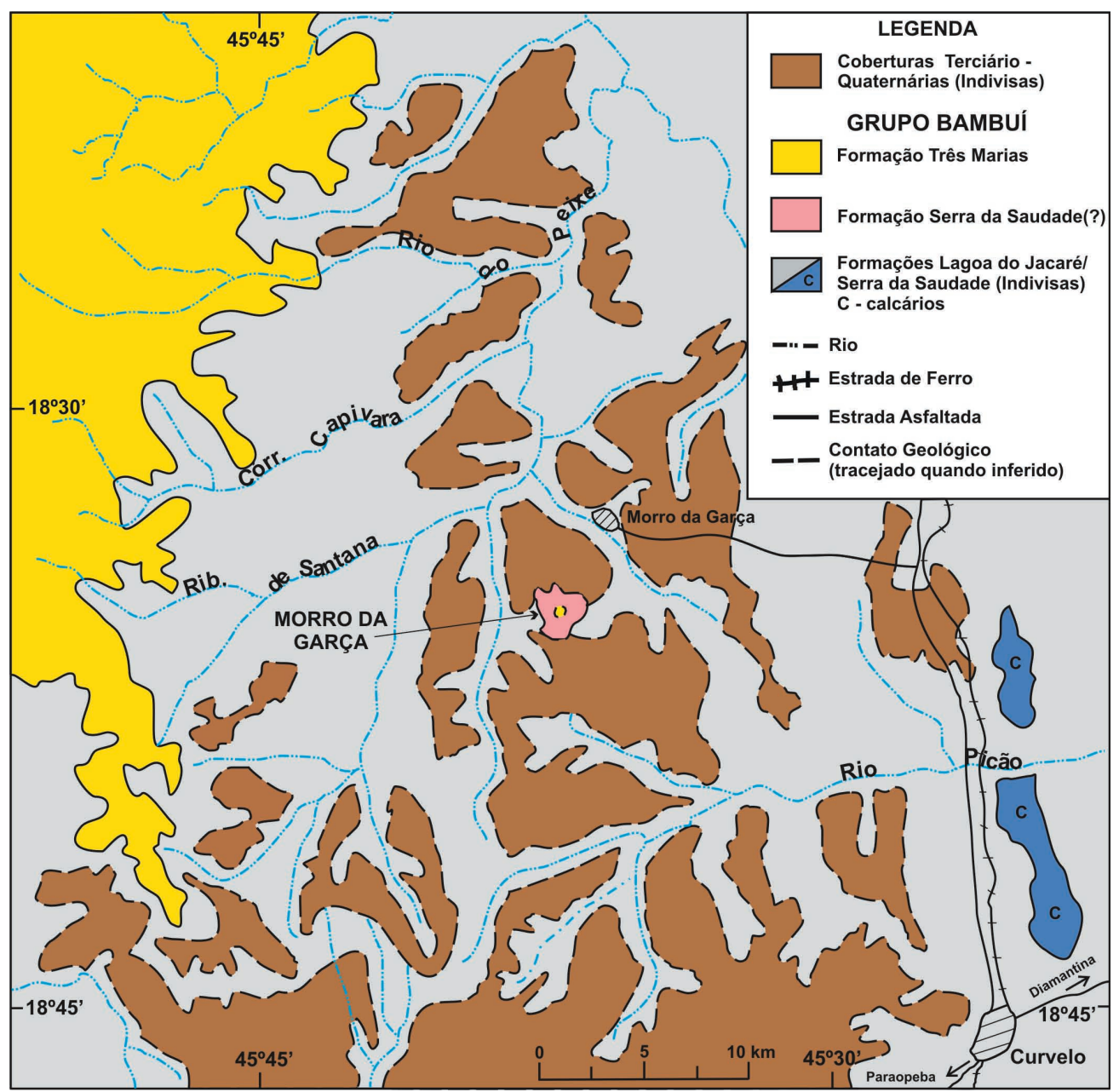

Figura 3: Mapa geológico da região de Morro da Garça (parcial e modificado de Menezes Filho et al., 1977).

uso na literatura. No Projeto Três Marias (Menezes Filho et al., 1977), o Grupo Bambuí foi subdividido segundo a proposta de Braun (1968), nas formações Paranoá, Paraopeba e Três Marias, da base para o topo, verificando-se na folha as duas últimas. Entretanto, posteriormente Dardenne (1978) questionou a validade regional para tal subdivisão, propondo a retomada dos conceitos estratigráficos originais de Branco \& Costa (1961), os quais consideraram o grupo como integrado pelas formações Sete Lagoas, Lagoa do Jacaré, Serra da Saudade e Três Marias. Esse último conceito tem sido amplamente aceito até a atualidade, e será também utilizado no mapa e nas descrições geológicas apresentadas.

O Grupo Bambuí como um todo possui espessura superior a $1.000 \mathrm{~m}$, e foi depositado no final do Neoproterozóico em ambiente de mar raso do tipo epicontinental, em contexto geotectônico de uma bacia de antepaís (Chang et al., 1998; Thomaz Filho et al., 1998). A idade de sedimentação do grupo está compreendida no intervalo aproximado entre $640 \mathrm{Ma}$ (Formação Sete Lagoas) e $580 \mathrm{Ma}$ (Formação Três Marias), com base em idades radiométricas $\mathrm{Rb} / \mathrm{Sr}$ e K/ Ar (Thomaz Filho et al., 1998). De outra forma, idades mais antigas foram recentemente obtidas por Babinski \& Kaufman (2003) e Babinski (2005), ao datarem a base do Grupo Bambuí (Formação Sete Lagoas) pelo método
$\mathrm{Pb} / \mathrm{Pb}$ em $740 \pm 22 \mathrm{Ma}$. Por conseguinte, considerandose tal datação, a idade de deposição dos litotipos da área do morro da Garça deve ser mais nova do que $740 \pm 22$ Ma. A deformação da seqüência está relacionada ao ciclo orogenético Brasiliano ( $\approx 600-500 \mathrm{Ma})$.

\section{O perfil do morro da Garça}

Através de perfil geológico de detalhe efetuado no morro da Garça (Figura 4), foi possível entender seu arcabouço geológico, bem preservado neste local, assim como a própria razão de existência de tal morfologia. Em toda a seção os mergulhos são muito suaves, variando entre 5 e $10^{\circ}$ para NW (as direções das camadas variam entre $\mathrm{N} 30-40^{\circ} \mathrm{E}$ ). Nos entornos e na base do morro, encontra-se um metassiltito amarelado em níveis tabulares com $5-10 \mathrm{~cm}$ de espessura, às vezes com microlaminações internas que dão à rocha um aspecto de ritmito (Figura 5). Logo acima na seção essas laminações desaparecem até que, na parte superior da seqüência ocorrem, intercaladas aos metassiltitos, lentes de uma rocha cinza-escura de aparência calcária, de granulação muito fina e estrutura maciça, inicialmente em bancos centimétricos que vão aumentando de modo gradual para o topo, até atingirem o porte de alguns metros (Figura 6).

A rocha que ocorre nas lentes, estudada 


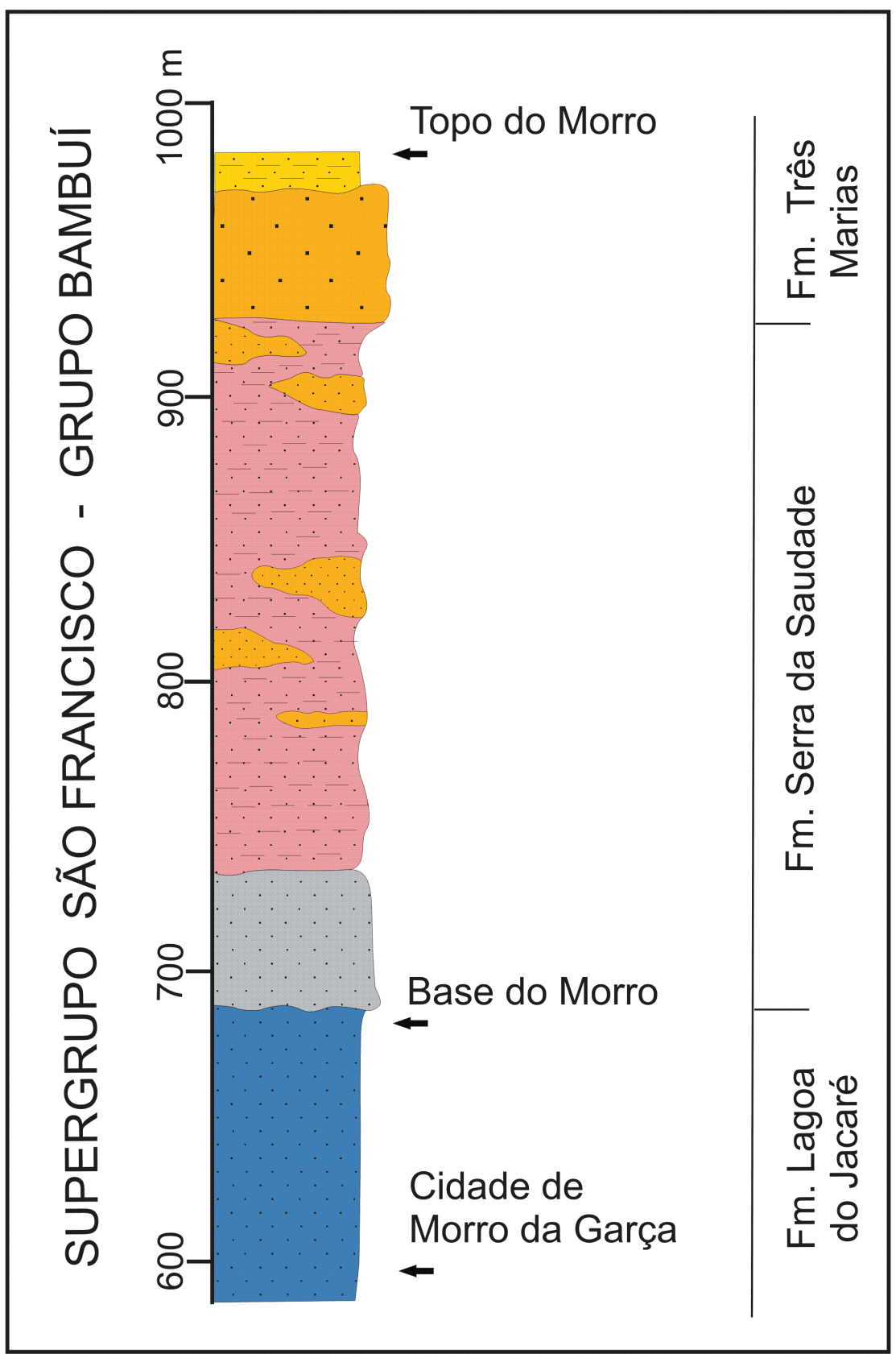

Figura 4: Coluna estratigráfica de detalhe do Grupo Bambuí na área do morro da Garça, relacionando os litotipos observados com as formações desse grupo já propostas na literatura.

petrograficamente foi identificada como um metassiltito calcífero ( $70 \%$ mica branca + clorita; $20 \%$ carbonato; $10 \%$ quartzo), de textura lepidoblástica a lepidogranoblástica, embora a granulação muito fina predominante não possibilite determinar com clareza as relações entre os minerais. A espessura total dessa primeira seqüência oscila em torno de $120 \mathrm{~m}$. No entanto, acima ainda ocorre a repetição de um segundo ciclo de metassiltitos laminados com metassiltitos calcíferos (maciços) no topo, este último mais delgado (com cerca de $70 \mathrm{~m}$ ), onde ambas as litologias apresentam características similares às do ciclo anterior.

$\mathrm{Na}$ parte superior do perfil, afloram metarenitos amarelados ou esverdeados, impuros e de granulação fina a média, apresentando $40 \mathrm{~m}$ de espessura. Microscopicamente a rocha apresenta textura granoblástica, e a associação mineral principal é formada por quartzo $(85 \%)$ e mica branca + clorita (10\%). Os grãos de quartzo são hipidioblásticos (subédricos), muitas vezes exibindo extinção ondulante, e as micas aparecem como palhetas finas, intersticiais, algo orientadas segundo a direção do acamamento. Os minerais acessórios (5\%) incluem plagioclásio, microclínio e minerais opacos, ocorrendo saussuritização incipiente dos plagioclásios.

Sustenta o cume do morro, em torno de $20 \mathrm{~m}$ de espessura de uma rocha muito dura, silicificada, cuja análise microscópica revelou ser um metarenito carbonático (Figura 7), embora de granulação fina a 


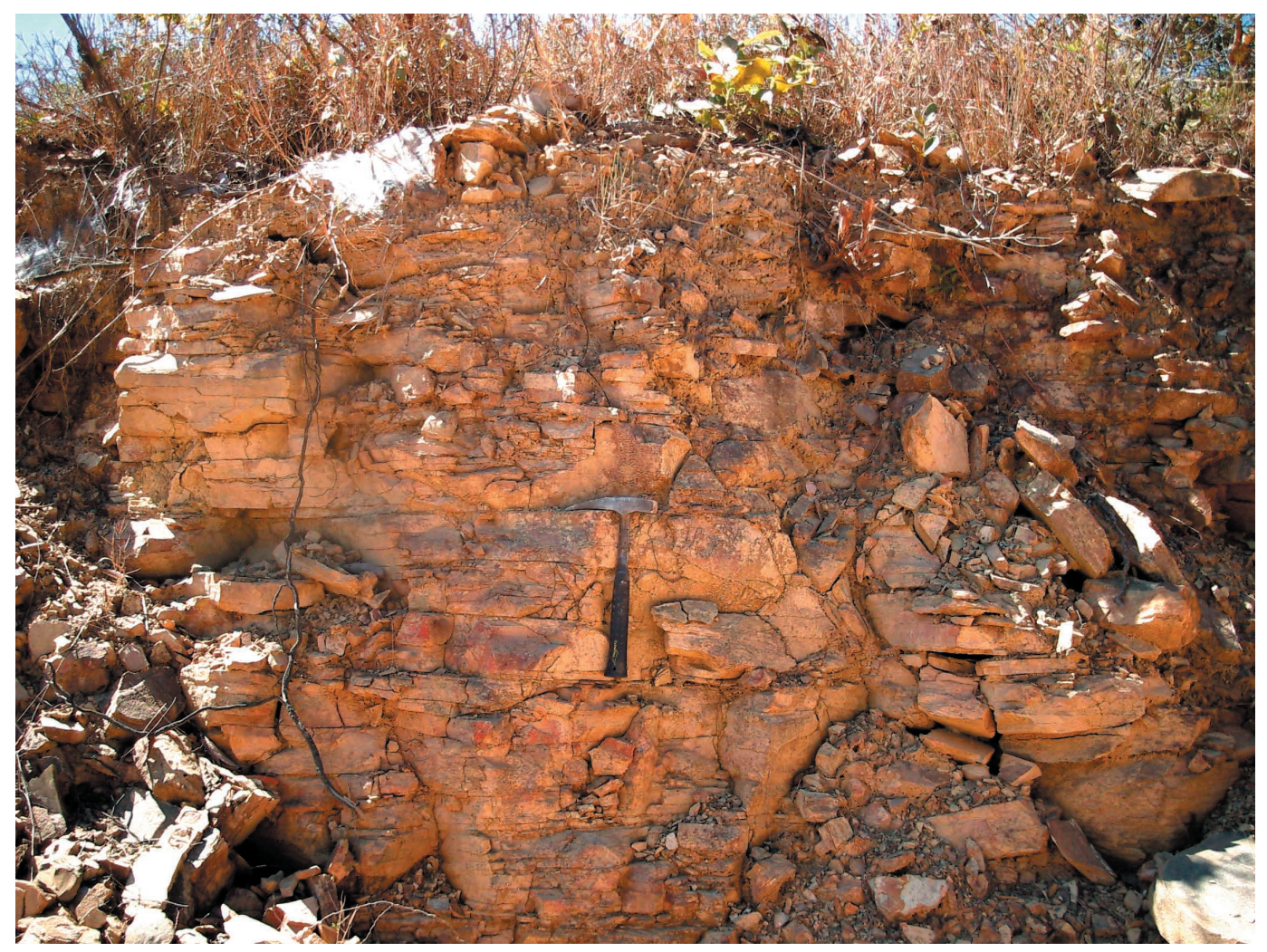

Figura 5: Metassiltito pertencente à Formação Serra da Saudade, estratificado em níveis centimétricos, que aflora nas porções mais baixas do morro da Garça.

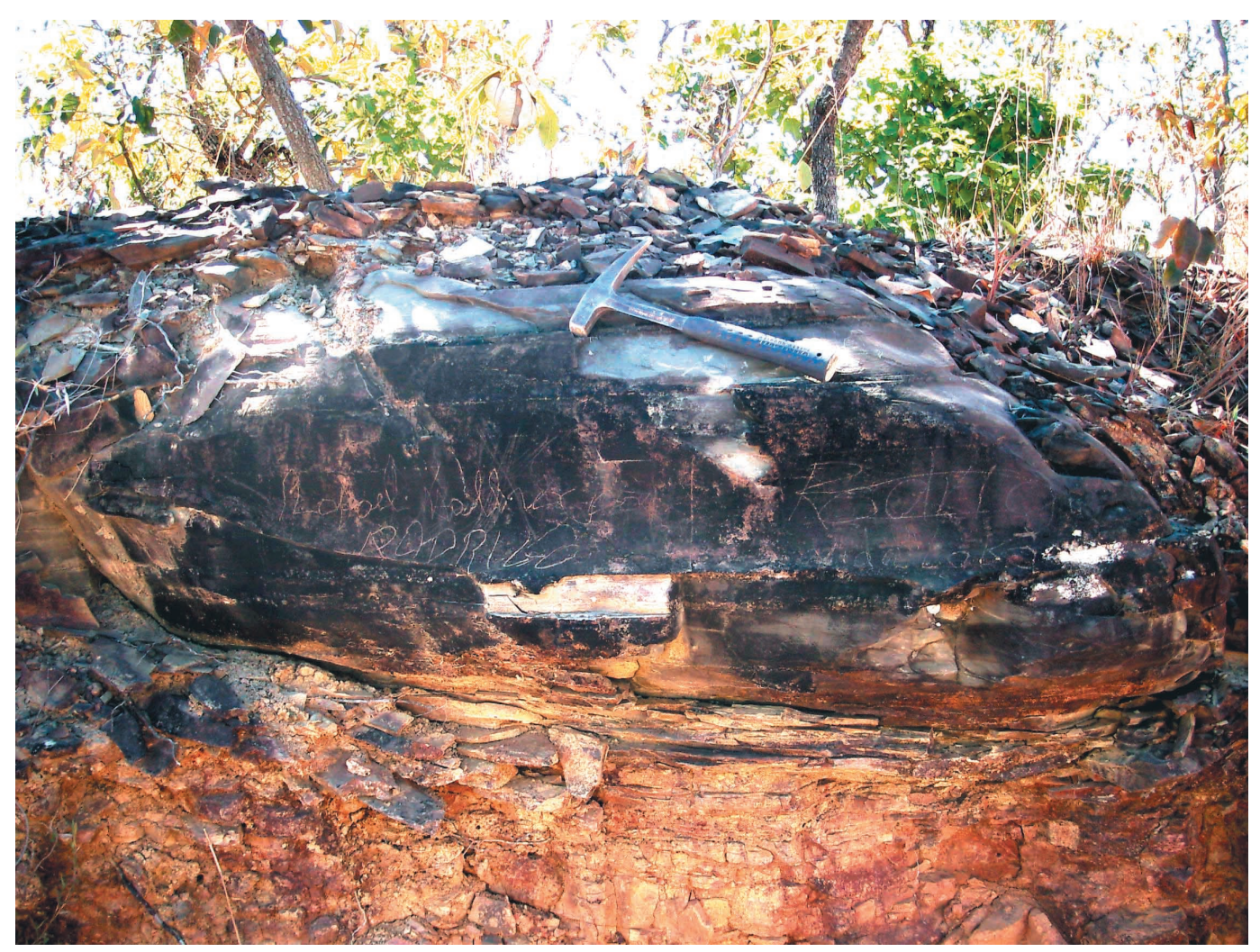

Figura 6: Contato entre metassiltito sobreposto por nível (lenticular) de metassiltito calcífero (até 20\% de carbonato). Esses níveis carbonáticos passam a ser mais espessos e abundantes em direção ao topo do perfil. 


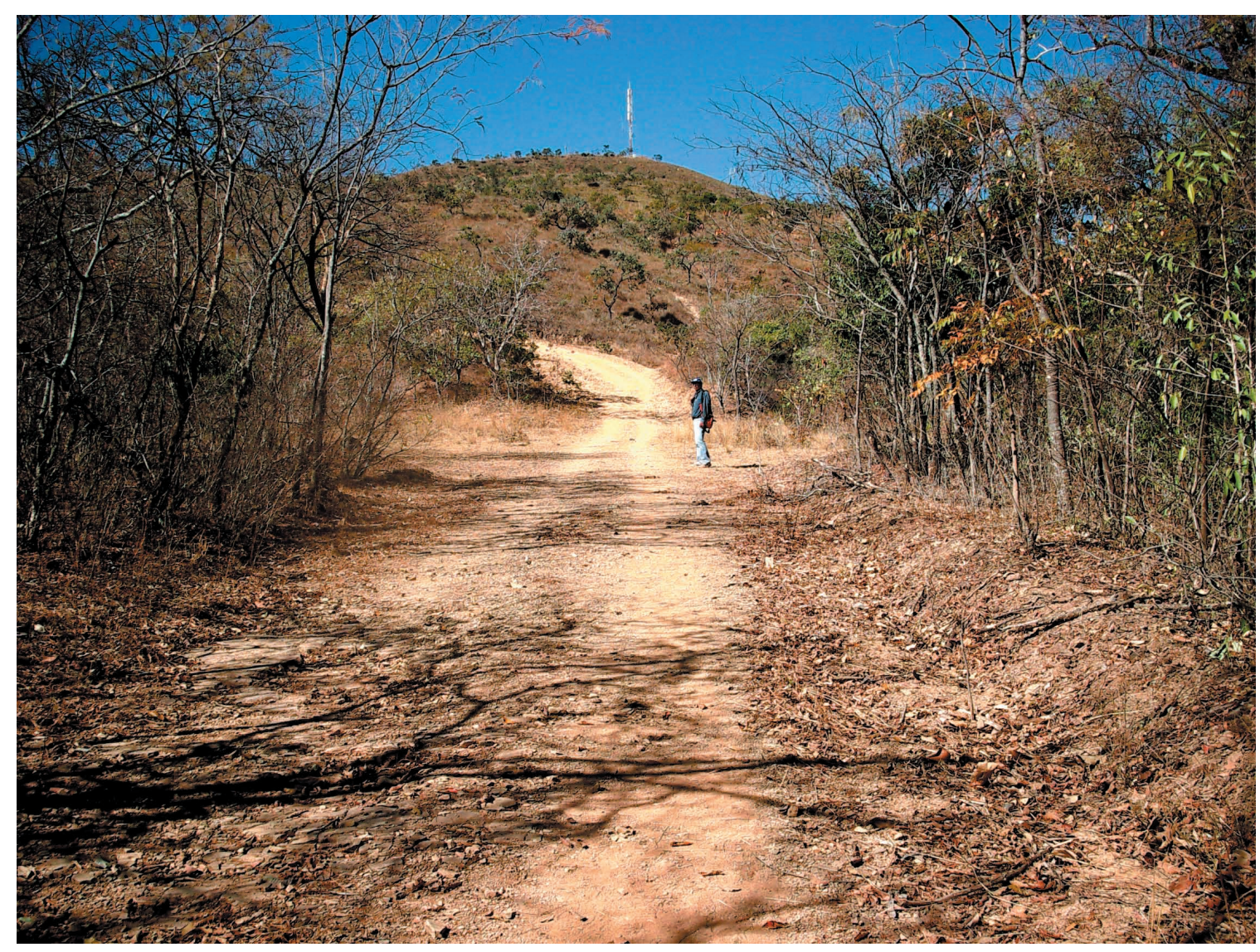

Figura 7: Vista do patamar dado pela quebra de relevo (onde está a estrada), circundante à porção superior do morro da Garça, sustentada por blocos isolados de metarenitos impuros e carbonáticos

(ao fundo da foto) da Formação Três Marias.

média e teor em carbonato mais baixo que o das lentes da seqüência inferior. Análise petrográfica revelou uma rocha de granulação predominantemente fina e de textura granolepidoblástica. Os minerais essenciais são quartzo (70\%), mica branca + clorita (15-17\%) e carbonato $(10 \%)$, tendo como acessórios, plagioclásio (incipientemente saussuritizado), zircão e minerais opacos. Os grãos de quartzo são hipidioblásticos (subédricos), muitas vezes com contato poligonal e extinção ondulante. Mica branca e clorita aparecem como palhetas finas, presentes nos contatos entre os grãos de quartzo, algumas vezes orientadas segundo uma direção preferencial correspondente a uma foliação subhorizontal incipiente. O carbonato está presente na matriz junto com as micas, ou então forma grãos associados ao quartzo.

De modo preliminar, correlaciona-se a seção basal pelito-carbonática do perfil, que inclui os entornos do morro da Garça, com a porção superior da Formação Serra da Saudade, a qual em outras regiões mais ao norte apresenta aspectos litológicos muito semelhantes (Chiavegatto \& Dardenne, 1997; Chiavegatto et al., 1997). O topo do perfil, metarenítico e com cerca de $60 \mathrm{~m}$ de espessura, é correlacionado à Formação Três Marias. Esta formação, na Serra do Boiadeiro (a oeste), passa a sustentar o relevo (Figura 3).

\section{Comparações regionais}

A Formação Serra da Saudade foi definida por Branco \& Costa (1961) na serra homônima (São Gonçalo do Abaeté), representada por sedimentos pelíticos como argilitos, folhelhos e siltitos. A Formação Três Marias foi descrita originalmente com o nome de Arenito Pirapora (Eschwege, 1832) e renomeada por Branco \& Costa (1961). Tal designação ficou depois consagrada pelo uso na literatura, sendo a unidade composta de arenitos, arcósios e siltitos. Esses últimos autores já identificaram uma passagem gradacional entre as formações Serra da Saudade e Três Marias, na região da barragem de Três Marias, do mesmo modo que foi observado na área do morro da Garça. Tendo por fim comparar a litologia do topo do morro com uma área de afloramento típico da Formação Três Marias, examinou-se ao microscópio amostra obtida de uma das seções-tipo (Pirapora).

O referido exame revelou uma rocha de granulação predominantemente fina e de textura granolepidoblástica, cuja associação mineral principal é quartzo $(70 \%)$, minerais opacos $(10 \%)$, carbonato $(8-$ $10 \%)$, plagioclásio $(5 \%)$ e mica branca + clorita $(5 \%)$, tendo como mineral acessório o zircão. O quartzo mostra grãos hipidioblásticos (subédricos), muitas vezes com contato poligonal e extinção 
ondulante. Os minerais opacos aparecem como níveis alongados e paralelos, denotando processo sedimentar de deposição. O carbonato está presente associado aos grãos de quartzo, do mesmo modo que o plagioclásio. Este último possui moderado a alto grau de saussuritização. Mica branca e clorita ocorrem como palhetas finas, intersticiais na matriz quartzocarbonática. Em termos gerais, confirma-se a grande semelhança entre tal litotipo e o presente no topo do morro da Garça.

\section{EVOLUÇÃO DA PAISAGEM}

A evolução da paisagem onde o morro da Garça é a maior elevação preservada por toda uma grande extensão plana, pode ser entendida pela constituição litológica regional. Enquanto os processos erosivos atuaram ativamente sobre unidades mais friáveis, as partes residuais oriundas de rochas mais resistentes, por conseguinte, foram menos atacadas pela erosão. Neste contexto, inclui-se tal morro, constituído na base por uma fácies silto-areno-carbonática, provavelmente da Formação Serra da Saudade. Tal fácies, de topo da referida formação, deve já corresponder a uma transição para a Formação Três Marias (conforme observações em regiões mais ao norte), constituindo localmente uma unidade mais tectonizada e assim apresentando rochas com mais alto grau de recristalização. Nas encostas da escarpa afloram metassiltitos e metarenitos finos de coloração escura, desta transição Serra da Saudade - Três Marias.
O topo do morro da Garça porém é sustentado pela Formação Três Marias sensu stricto, onde ocorre um metarenito típico da unidade, impuro e de coloração esverdeada, também bastante silicificado. Deste modo, na área enfocada a Formação Três Marias aflora somente neste local e, sem dúvidas, constitui fator imprescindível para que o morro tenha permanecido como uma estrutura morfológica remanescente, que se destaca em meio à paisagem completamente arrasada dos arredores. Em épocas chuvosas, o crescimento preferencial da vegetação nas encostas do morro, onde predominam as rochas pelíticas, faz com que seu topo arenítico seja realçado (Figura 8), o que não se observa com tal nitidez na estação seca (Figura 9). O arrasamento do relevo, na área circundante ao morro da Garça, pode ser observado na figura 10 , de onde se tem uma visão da cidade de Morro da Garça desde o cume daquela feição.

\section{CONSIDERAÇÕES FINAIS}

O Grupo Bambuí, embora seja sob diversos aspectos uma das unidades litoestratigráficas melhor conhecidas do país, ainda possui muitas questões a serem estudadas, principalmente quanto a integrações regionais e detalhamentos de ordens diversas. Essas questões são oriundas do elevado grau de intemperismo submetido à bacia do São Francisco, de modo que, conjugando-se aos litotipos predominantemente pelíticos e carbonáticos da seqüência, fazem com que

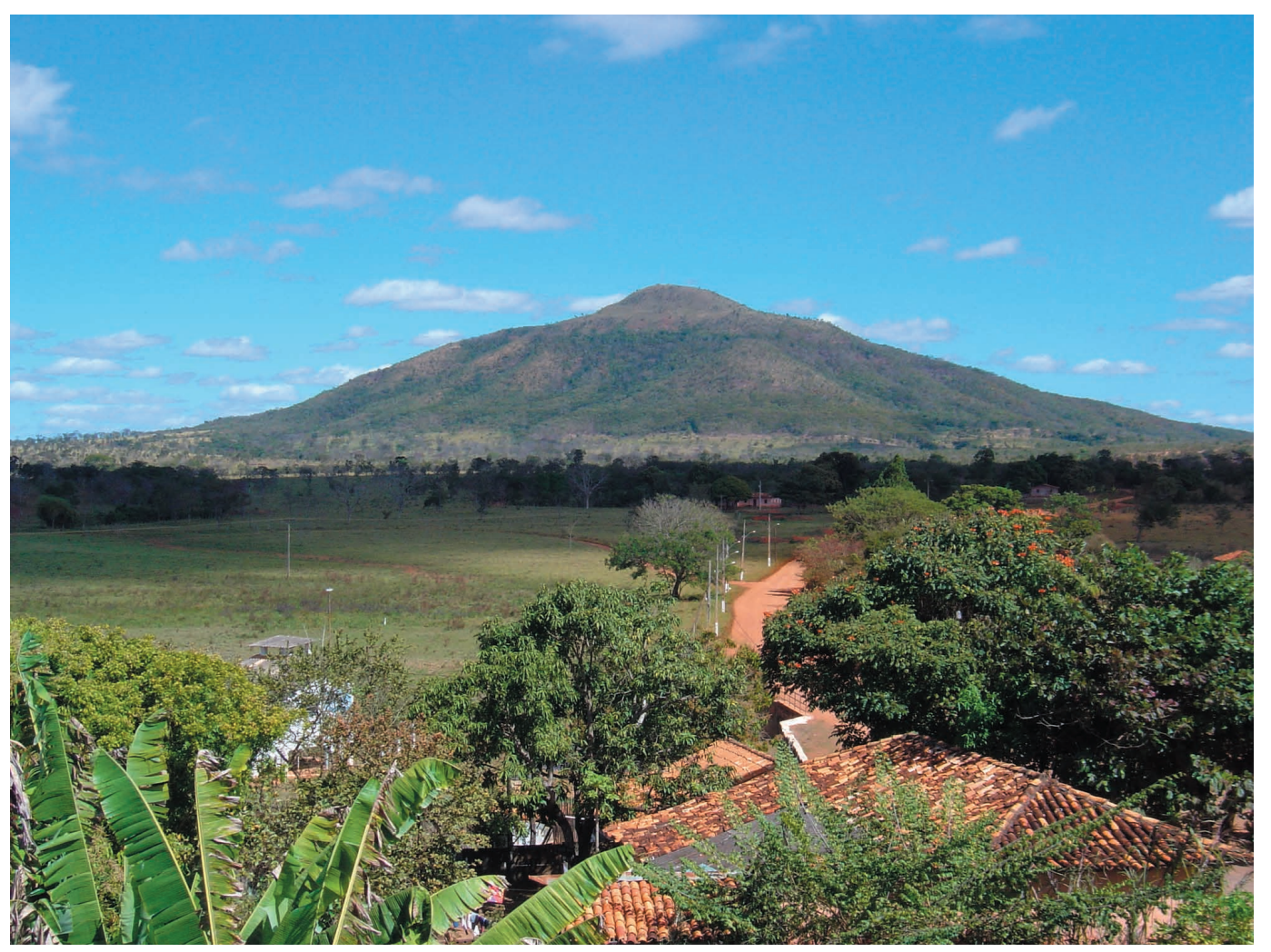

Figura 8: Imagem geral do morro da Garça, a partir da cidade homônima, durante a estação chuvosa, quando a exposição do cume torna-se melhor visualizada pelo crescimento diferenciado da vegetação, que nessa parte é mais escassa (Foto Flávia Ayer - Projeto Manuelzão, UFMG). 


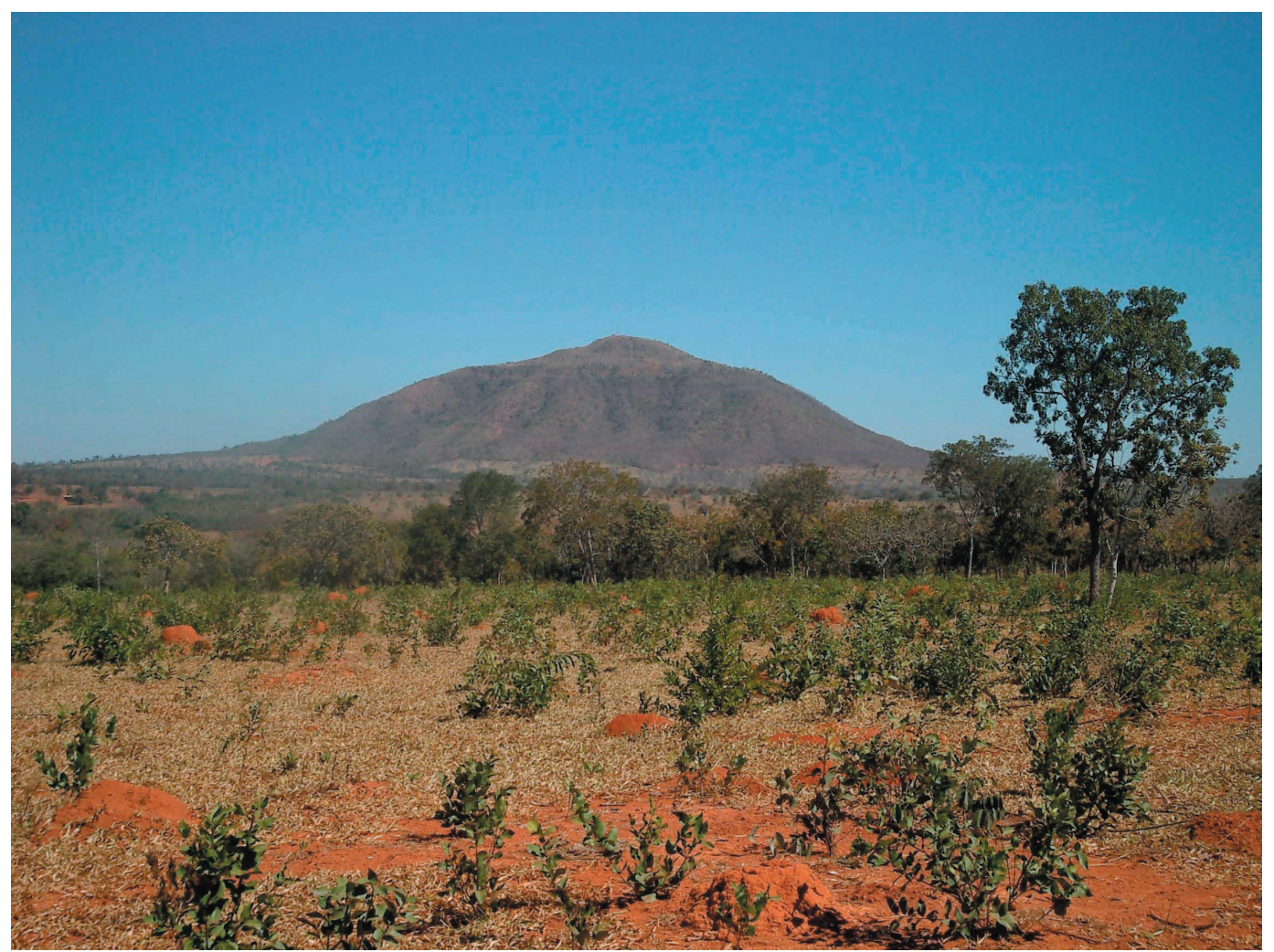

Figura 9: Imagem geral do morro, desde o mesmo local, em época de estiagem, quando o "topo pelado" aparece muito menos realçado.

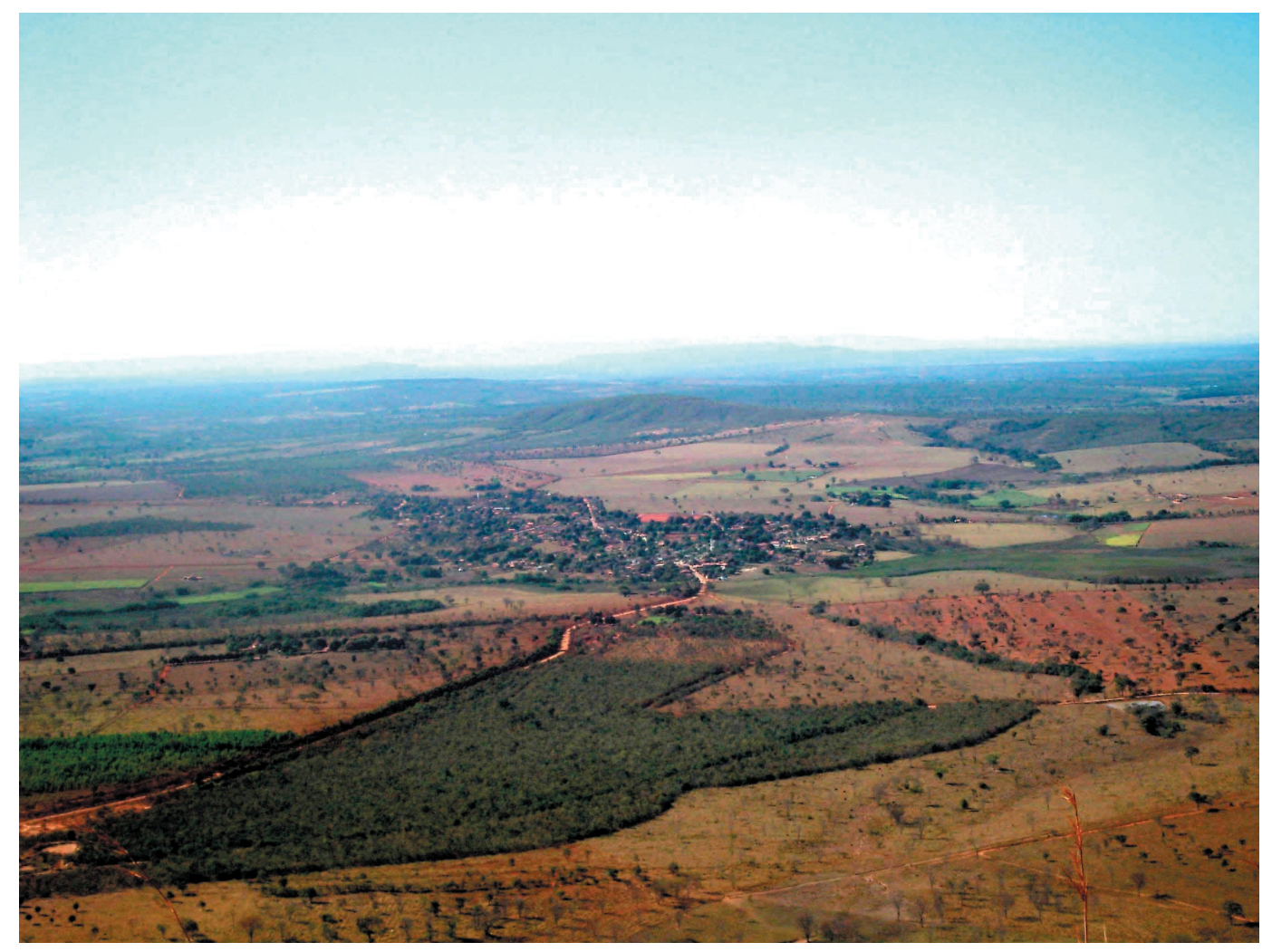

Figura 10: Vista da cidade de Morro da Garça a partir do cume do morro, ressaltando-se o arrasamento geral da paisagem constituída por litotipos do Grupo Bambuí (formações Lagoa do Jacaré e Serra da Saudade, indivisas). 
os afloramentos sejam esparsos e em geral intemperizados. Assim, a região do morro da Garça constitui um raro local para estudos de detalhe e, ainda, as exposições quase contínuas e verticais fazem dali um excelente sítio para treinamentos didáticos a respeito de perfilagens de estratigrafia e sedimentologia.

Em suma, propõe-se uma evolução estratigráfica e geomorfológica da área do morro da Garça, baseada nos seguintes aspectos obtidos através do presente levantamento:

i) Deposição marinha epicontinental, neoproterozóica $( \pm 580 \mathrm{Ma})$, no âmbito da bacia Sanfranciscana, das formações Serra da Saudade e Três Marias, do Grupo Bambuí;

ii) Inversão da bacia, com deformação e metamorfismo de fácies xisto verde, durante o ciclo orogênico Brasiliano ( $\approx 600-500 \mathrm{Ma})$;

iii) Erosão e conseqüente geração do modelado atual, a partir do Mesozóico, seqüenciados pela formação da superfície de aplainamento Sul-Americana (cujo término ocorreu no Oligoceno-Mioceno), que propiciou o nivelamento da parte superior do relevo;

iv) A constituição litológica do morro da Garça, sustentada por metarenitos silicificados da Formação Três Marias, permitiu com que tal feição morfológica restasse preservada como um testemunho na paisagem regional atual, em decorrência da fase de erosão e desenvolvimento do subseqüente ciclo de aplainamento Velhas.

\section{REFERÊNCIAS BIBLIOGRÁFICAS}

Babinski M. 2005. A idade do Supergrupo São Francisco: revisão e implicações nas glaciações neoproterozóicas. In: Simpósio sobre o Cráton do São Francisco, 3, Short papers do... Salvador, p.135-138.

Babinski M. \& Kaufman A.J. 2003. First direct dating of a Neoproterozoic post-glacial cap carbonate. In: South American Symposium on isotope geology, 4, Short papers of... Salvador, v.1, p.321-323.

Braun O.P.G. 1968. Contribuição à geologia do Grupo Bambuí. In: Congresso Brasileiro de Geologia, 22, Anais do..., Belo Horizonte, p.155-166.

Braun O.P.G. 1970. Contribuição à geomorfologia do Brasil Central. Revista Brasileira de Geografia, 32:3-39.
Branco J.J.R., Costa M.T. 1961. Roteiro da excursão Belo Horizonte - Brasília. Belo Horizonte, UFMG - Instituto de Pesquisas Radioativas, Publicação 15, 25p.

Chang H.K., Miranda F.P., Magalhães L., Alkmim F.F. 1998. Considerações sobre a evolução tectônica da Bacia do São Francisco. In: Congresso Brasileiro de Geologia, 35, Anais do... Belém, v.5, p.2076-2090.

Chaves M.L.S.C., Benitez L., Andrade K.W., Meneghetti Filho I. 2006. Morro da Garça: geologia e a visão mística de Guimarães Rosa no centro geodésico de Minas Gerais. www.unb.br/sigep/ propostas, 9p.

Chiavegatto J.R.S., Dardenne M.A. 1997. Contribuição à sedimentologia e estratigrafia do Grupo Bambuí no norte de Minas Gerais. In: Simpósio de Geologia de Minas Gerais, 9, Anais do..., Belo Horizonte, p.81-82.

Chiavegatto J.R.S., Gomes N.S., Dardenne M.A. 1997. Conglomerados oligomíticos da Formação Três Marias na Serra do Gorotuba, norte de Minas Gerais. In: Simpósio de Geologia de Minas Gerais, 9, Anais do..., Belo Horizonte, p.83-84.

Dardenne M.A. 1978. Síntese sobre a estratigrafia do Grupo Bambuí no Brasil Central. In: Congresso Brasileiro de Geologia, 30, Anais do..., Recife, v.2, p.597-610.

Derby O.A. 1880. Contribuições para o estudo da geologia do Vale do São Francisco. Archivos do Museu Nacional, 4:89-119.

De Martone E. 1943. Problemas morfológicos do Brasil tropical atlântico. Revista Brasileira de Geografia, 5:523-550.

De Martone E. 1944. Problemas morfológicos do Brasil tropical atlântico (continuação). Revista Brasileira de Geografia, 6:155178.

Eschwege W.L. von 1832. Beitrage zur gebirgekunde Brasilien; mit vier petrographischen geognostischen Karten und Profildurchschnitten. Berlin, G. Reimer, 488p.

Guimarães Rosa J. 1956. Corpo de Baile. Rio de Janeiro, Ed. José Olímpio, 513p.

King L.C. 1956. A geomorfologia do Brasil Oriental. Revista Brasileira de Geografia, 18:147-265.

Lima, R. 1998. O campo da Garça. Belo Horizonte, Edições Cuatiara, $225 \mathrm{p}$.

Menezes Filho N.R., Mattos G.M.M., Ferrari P.G. 1977. Projeto Três Marias. Belo Horizonte, Convênio DNPM/CPRM, Relatório Final, vol.1, 546p.

Rimann E.T. 1917. A kimberlita no Brasil. Anais da Escola de Minas, Ouro Preto, 15:27-32.

Thomaz Filho A., Kawashita K., Cordani U.G. 1998. A origem do Grupo Bambuí no contexto da evolução geotectônica e de idades radiométricas. Anais da Academia Brasileira de Ciências, 70:527-548.

Valadão R.C. 1998. Evolução de longo-termo da relevo do Brasil Oriental (desnudação-superfícies de aplanamento e soerguimentos crustais). Salvador, Tese de Doutoramento, IGC-UFBA, 243p. 